\title{
STRATEGI PEMBELAJARAN JARAK JAUH UNTUK SISWA BERKEBUTUHAN KHUSUS DI TENGAH PANDEMI
}

\author{
DISTANCE LEARNING'S STRATEGIES FOR STUDENTS WITH SPECIAL NEEDS \\ IN THE MIDST PANDEMIC

\section{Saida Luthfia Aghniya} \\ Program Studi Pendidikan Bahasa Inggris ULM \\ E-mail: saidaluthfiaaghniya@gmail.com
}

\begin{abstract}
ABSTRAK
Penyandang disabilitas mempunyai hak dan kewajiban yang sama sebagai warga negara. Berdasarkan Undang- Undang Dasar 1945 pasal 31 ayat 1 dan Undang - Undang Nomor 20 tahun 2003 tentang Sistem Pendidikan Nasional dapat disimpulkan bahwa negara memberikan jaminan sepenuhnya kepada anak berkebutuhan khusus untuk memperoleh layanan pendidikan yang bermutu. Pembelajaran yang sudah diperoleh bertahun tahun di sekolah, bisa hilang jika tidak berkesinambungan dengan pembelajaran di rumah. Penelitian ini bertujuan untuk mengetahui strategi pembelajaran jarak jauh dalam penerapan pendidikan inklusi bagi anak berkebutuhan khusus di tengah pandemic Covid-19 yang sedang terjadi. Penelitian ini menggunakan metode studi kepustakaaan. Data diperoleh melalui dokumentasi dan studi literature. Artikel ini menguraikan bagaimana permasalahan yang di hadapi dan strategi yang digunakan oleh pendidik dalam pembelajaran bagi anak berkebetuhan khusus di tengah pandemi.

Kata kunci: Strategi, anak berkebutuhan khusus, pandemik
\end{abstract}

ABSTRACT 
Persons with disabilities have the same rights and obligations as citizens. Based on Undang Undang Dasar 1945 pasal 31 Ayat 1 and UndangUndang Dasar Nomor 20 tahun 2003 concerning about the National Education System, it can be concluded that the state fully guarantees children with special needs to obtain quality education services. Learning that has been obtained for years at school can be lost if it is not continuous with learning at home. This study aims to determine distance learning strategies in the application of inclusive education for children with special needs in the midst of the ongoing Covid-19 pandemic. This research uses literature study method. Data obtained through documentation and literature study. This article describes how the problems faced and the strategies used by educators in learning for children with special disabilities in the midst of a pandemic.

Keywords: Strategy, students with special need, pandemic.

\section{PENDAHULUAN}

Sekolah adalah lembaga pendidikan formal yang dimana pendiriannya bertujuan untuk mendidik, mengelola, dan memberikan pengajaran oleh guru terhadap siswa. Sekolah merupakan tempat untuk mengenyam pendidikan. Pendidikan menjadi hak untuk semua orang. Pendidikan inklusif adalah adalah sebuah layanan pendidikan bagi peserta didik yang mempunyai kebutuhan khusus tanpa memandang kondisi fisik, intelektual, linguistik, sosial emosional, atau kondisi lainnya untuk mendapatkan

pelayanan yang setara dengan pelayanan pendidikan di sekolah regular. Pendidikan inklusif khususnya ditujukan kepada anak-anak berkebutuhan khusus (ABK) agar dapat mengenyam pendidikan yang seharusnya. Pendidikan inklusi memberikan kesempatan yang seluas-luasnya kepada semua peserta didik yang memiliki kelainan fisik, emosional, mental, dan sosial atau memiliki potensi kecerdasan dan/atau bakat istimewa untuk 
memperoleh pendidikan yang bermutu sesuai dengan kebutuhan dan kemampuannya (Amka, 2017).

Menurut (Direktorat Pendidikan Luar Biasa, 2004: 5) Anak Berkebutuhan Khusus (ABK) adalah anak yang secara signifikan mengalami kelainan atau penyimpangan (fisik, mental-inteleklual, sosial, emosional) dalam proses pertumbuhan atau perkembangannya dibandingkan dengan anak-anak lain seusianya, sehingga mereka memerlukan pelayanan pendidikan khusus (Erawati, 2016). "Pendidikan inklusif tidak dapat bekerja sendiri, dan pendidikan umum yang mengambil peran utama dalam pendidikan inklusif perlu didukung para pemangku kepentingan: kepala sekolah, guru, orang tua, masyarakat, pemerintah dan sebagainya" (Amka, 2019).

Saat ini, kesadaran orang tua terhadap pentingnya peran orang tua dalam terlaksananya pendidikan inklusif masih rendah. Kebanyakan dari mereka menganggap pendidikan tidaklah penting bagi anak berkebutuhan khusus. Salah satu faktor yang menyebabkan hal tersebut dikarenakan terhalangnya faktor ekonomi yang menyebabkan ketidak fahaman mereka akan pentingnya pendidikan. Faktor lainnya yang menyebabkan orang tua acuh terhadap pendidikan untuk anak berkebutuhan khusus adalah adanya rasa khawatir, malu, dan menganggap hal tersebut aib.

IImu pengetahuan semakin berkembang. Adanya kemajuan teknologi menuntut pelaksanaan pendidikan untuk menyesuaikan dengan kebutuhan lingkungan. Adanya internet memfalisitasi pendidikan dengan hal-hal baru, contohnya adalah banyak nya media pembelajaran yang bisa ditemukan di internet.

Pandemi COVID-19 yang masih menyelimuti wilayah dunia hingga saat ini menimbulkan dampak terhadap pendidikan di Indonesia. Kementrian Pendidikan dan Kebudayaan RI mengeluarkan kebijakan agar 
penyelenggaraan proses pembelajaran dilakukan secara daring, oleh karena itu aspek pembelajaran terpaksa harus dilaksanakan secara virtual. Teknologi menjadi solusi dari pemberlakuan pembelajaran jarak jauh. Pembelajaran dilaksanakan secara virtual menggunakan berbagai aplikasi penunjang pembelajaran virtual seperti Google meet, Zoom, dan Google Classroom.

Hal ini juga berlaku bagi anak berkebutuhan khusus yang bersekolah di sekolah luar biasa maupun sekolah inklusi. Dalam keadaan ini, guru perlu untuk menyiapkan rancangan pembelajaran yang berbeda. Khususnya dengan keadaan anak berkebutuhan khusus yang lebih spesial dibanding anak anak normal lainnya, tantangan yang dihadapi oleh tenaga ajar untuk ABK menjadi berlipat. Anak berkebutuhan khusus biasanya memiliki masalah dalam perkembangan berkomunikasi mereka. Mereka cenderung mengalami kesulitan dalam memulai suatu percakapan. Pembelajaran yang awalnya bisa dilakukan secara langsung diharuskan hanya melalui virtual. Komunikasi yang diperlukan dalam pembelajaran menjadi terbatas. Oleh karena itu, dibutuhkan strategi pembelajaran yang sesuai untuk menghadapi permasalahan-permasalahan dalam mengajar jarak jauh. Dalam hal ini, dibutuhkan kolaborasi antara guru dengan orang tua,

Dari hal-hal yang telah dijelaskan, peneliti tertarik untuk melakukan penelitian mengenai strategi guru dalam menghadapi pembelajaran jarak jauh ditengah pandemi COVID-19.

\section{METODE}

Metode yang digunakan dalam penulisan artikel ini adalah studi pustaka yaitu mengumpulkan informasi atau data yang relevan dengan topik penelitian melalui dokumen-dokumen. Data yang digunakan dalam artikel ini 
adalah data yang diperoleh dari jurnal, buku, dan berita. Data diperoleh melalui dokumentasi dan studi literatur. Dokumentasi merupakan metode yang digunakan untuk mencari dokumen yan dapat menunjang penelitian dan relevan dengan topik penelitian melalui jurnal, buku, repository, artikel koran/majalah, serta internet. Sedangkan studi literature menurut Creswell, John. W. (2014), kajian studi literatur adalah ringkasan tertulis mengenai artikel dari jurnal, buku, dan dokumen lain yang mendeskripsikan teori serta informasi baik masa lalu maupun saat ini mengorganisasikan pustaka ke dalam topik dan dokumen yang dibutuhkan (Habsy, 2017).

\section{HASIL DAN PEMBAHASAN}

Kebijakan pelaksaan pembelajaran jarak jauh atau pembelajaran daring yang dilakukan sekarang ini adalah hasil dari menyikapi pandemic COVID-19 yang sedang melanda dunia. Pembelajaran daring memberikan tantangan tersendiri bagi guru yang mengajar di sekolah inklusi maupun sekolah luar biasa. Ketua Asosiasi Profesi Pendidikan Khusus Indonesia Munawir Yusuf menjelaskan, anak berkebutuhan khusus rentan mengalami degradasi atau penurunan dalam pendidikan karena penerapan pembelajaran jarak jauh yang berkepanjangan. Berbeda dengan siswa biasa, siswa berkebutuhan khusus tidak hanya butuh pengetahuan saja tetapi juga butuh interaksi secara langsung dengan orang yang dipercaya (Arif Satrio Nugroho, 2020).

Kolaborasi antar orang tua dengan guru diperlukan agar mengurangi banyaknya hambatan dan kendala dalam pembelajaran jarak jauh. Jika pada pembelajaran tatap muka segala sesuatu yang telah disampaikan oleh guru di sekolah akan ditindak lanjuti oleh orang tua di rumah, maka saat pembelajaran jarak jauh ini orang tua akan mendampingi siswa berkebutuhan khusus dalam proses belajarnya di sekolah dan kemudian 
langsung menindak lanjutinya di rumah. Selama pembelajaran jarak jauh, orang tua menjadi pegangan utama bagi siswa berkebutuhan khusus.

Pembelajaran terhadap anak berkebutuhan khusus menyesuaikan dengan kondisi siswa itu sendiri. Penelitian menunjukkan bahwa kolaborasi yang efektif memiliki sejumlah manfaat yang signifikan. Belajar mengajar yang dilakukan oleh guru pendidikan luar biasa dengan siswanya dapat melalui kurikulum tetapi pembelajaran difokuskan pada hal yang berkaitan langsung dengan kebutuhan belajar individu siswa (Ní Bhroin \& King, 2020). Penyesuaian tersebut akan menghubungkan pada strategi yang akan digunakan dalam pembelajaran.

Seperti yang dilansir Kompas.com, Salah satu guru dari sekolah luar biasa swasta mengutarakan ada tiga strategi yang dapat digunakan dalam pembelajaran jarak jauh untuk siswa berkebutuhan khusus yaitu:

1. Strategi pengajaran yang di individualisasikan Program pembelajaran individual adalah alat yang digunakan untuk mengenali dan mengintegrasi pendidikan sesuai dengan individu yang bersangkutan. Menurut Smith \& Luckasson (1995: 89), Program Pendidikan Individual (IEP) adalah program memastikan anak-anak prasekolah dan anak-anak usia sekolah menerima pendidikan dan layanan terkait yang diperlukan untuk memenuhi kebutuhan khusus individu mereka di beberapa bidang (Khoeriah, 2018). Dalam strategi ini, guru menyesuaikan materi pembelajaran yang diberikan dengan kemampuan siswa berkebutuhan khusus sehingga mereka bisa berinteraksi dengan minat mereka.

2. Strategi kooperatif

Slavin (2008) berpendapat bahwa pembelajaran dengan strategi kooperatif adalah pembelajaran dimana peserta didik terdorong untuk bekerja sama dalam kelompok kecil pada tugas akademik. 
Strategi kooperatif mengarah pada pembelajaran yang menunjukkan perilaku kerja sama yang teratur dalam sebuah kelompok yang terdiri dari dua orang atau lebih yang mana hasil kerja tersebut dipengaruhi oleh keterlibatan anggita kelompoknya. Pada pembelajaran jarak jauh untuk siswa berkebutuhan khusus, strategi kooperatif dilaksanakan dengan orang-orang di lingkungan sekitarnya, contohnya adalah keluarga. Strategi kooperatif ini dapat membuat siswa berkebutuhan khusus agar mempunyai rasa semangat, kekeluargaan, dan keakraban dengan guru dan lingkungan sekitarnya sehingga mereka tidak cepat bosan.

3. Strategi modifikasi tingkah laku Martin dan Pear (2003) mendefinisikan modifikasi perilaku sebagai sebuah aplikasi sistematis dari prinsip-prinsip dan teknik-teknik belajar untuk mengukur dan meningkatkan tingkah laku individu dalam rangka membantunya agar dapat berfungsi secara penuh di tengah masyarakat (Parmawati, Prasetyawati, \& Prianto, 2017). Ada dua teknik dalam penerapan strategi modifikasi tingkah laku antara lain fading dan token economy. Menurut Martin dan Pear (2003), fading adalah perubahan gradual pada percobaan suksesif dari sebuah stimulus yang mengontrol sebuah respon sehingga pada akhirnya respon akan muncul meskipun stimulus berubah atau baru sama sekali. Dalam pengaplikasian fading, hal pertama yang harus dilakukan guru adalah menentukan stimulus akhir yang mencerminkan perubahan tingkah laku dalam situasi sehari-hari sebagai pencapaian siswa. Hal kedua adalah menentukan reinforce atau penguatan yang sesuai, kemudian yang ketiga adalah menentukan stimulus pertama dan langkah-langkah fading. Teknik kedua adalah token economy, yaitu sitem reinforcement dimana guru memberikan sebuah pujian atau hadiah kepada siswa. Tujuan 
strategi ini ialah mengurangi atau menghilangkan tingkah laku tidak baik.

Ketiga strategi tersebut dapat diterapkan oleh guru pendamping siswa berkebutuhan khusus dalam pembelajaran jarak jauh. Penggunaan strategi dengan konteks yang inovatif dapat membuat pelajaran tidak membosankan bagi siswa. Melalui strategi-strategi tersebut, guru dapat membuat media belajar yang menarik sebagai alat untuk menyampaikan isi materi pembelajaran. Penggunaan media pembelajaran harus bisa untuk menyajikan pesan pembelajaran dengan jelas dan dapat mengembangkan kemampuan siswa dalam memahami materi yang disampaikan pendidik.

\section{KESIMPULAN}

Pandemi COVID-19 yang masih menyelimuti wilayah dunia hingga saat ini menimbulkan dampak terhadap pendidikan di Indonesia. Kementrian Pendidikan dan Kebudayaan RI mengeluarkan kebijakan agar penyelenggaraan proses pembelajaran dilakukan secara daring. Oleh karena itu, aspek pembelajaran terpaksa harus dilaksanakan secara virtual. Pembelajaran terpaksa dilakukan secara jarak jauh. Hal ini tidak hanya berdampak pada siswa yang bersekolah pada sekolah regular, tetapi juga berdampak pada siswa yang bersekolah pada sekolah luar biasa. Dalam keadaan ini, guru perlu untuk menyiapkan rancangan pembelajaran yang berbeda. Khususnya dengan keadaan anak berkebutuhan khusus yang lebih spesial dibandingkan dengan anak-anak normal lainnya, tantangan yang dihadapi oleh tenaga ajar untuk ABK menjadi berlipat. Kolaborasi antara orang tua, guru, dan lingkungan sekitarnya akan sangat dibutuhkan dalam mengatasi permasalahan dalam pembelajaran jarak jauh untuk siswa berkebutuhan khusus. Pembelajaran terhadap anak berkebutuhan khusus menyesuaikan dengan kondisi siswa itu sendiri. Dari hasil studi pustaka yang dilakukan, dapat disimpulkan bahwa ada tiga strategi yang dapat dilakukan 
oleh guru pendamping anak berkebutuhan khusus yaitu: strategi pengajaran yang di individualisasikan; strategi kooperatif; dan strategi modifikasi tingkah laku. Melalui strategi-strategi tersebut, guru dapat membuat media belajar yang menarik sebagai alat untuk menyampaikan isi materi pembelajaran.

\section{REFERENSI}

Amka, A. (2017). Implementasi Pendidikan Karakter Inklusi Bagi Anak Berkebutuhan Khusus Di Sekolah Reguler, Madrosatuna: Journal of Islamic Elementary School, Vol. 1 (1). 1-12.

Erawati, I. L. (2016). Pendidikan Karakter Bangsa pada Anak Berkebutuhan Khusus dalam Pendidikan Inklusif (Doctoral dissertation, UNIVERSITAS LAMPUNG).

Amka, A (2019). Sikap Orang Tua Terhadap Pendidikan Inklusif, Madrosatuna: Journal of Islamic Elementary School, Vol. 1 (1). 15-27.

Darmono, A. (2015). Peran Orang Tua Dalam Pendidikan Anak Berkebutuhan Khusus. Al-Mabsut: Jurnal Studi Islam dan Sosial, 9(1), 141161.

Astini, N. K. S. (2020). Tantangan Dan Peluang Pemanfaatan Teknologi Informasi Dalam Pembelajaran Online Masa Covid-19. Cetta: Jurnal Ilmu Pendidikan, 3(2), 241-255.

Sadikin, A., \& Hamidah, A. (2020). Pembelajaran Daring di Tengah Wabah Covid-19:(Online Learning in the Middle of the Covid-19 Pandemic). Biodik, $6(2), 214-224$. 
Anjani, D., Fadhila, M., \& Primasari, W. (2019). Strategi Komunikasi Pendidik Dalam Menghadapi Temper Tantrum Anak Berkebutuhan Khusus. Makna: Jurnal Kajian Komunikasi, Bahasa, dan Budaya, 5(2), 1-16

Habsy, B. A. (2017). Seni memehami penelitian kuliatatif dalam bimbingan dan konseling: studi literatur. Jurnal Konseling Andi Matappa, 1(2), 90-100.

Nugroho, Arif S. (2020. Juni 26) Siswa Berkebutuhan Khusus Rentan Alami Degradasi Pendidikan. Diakses pada 26 November 2020, dari https://republika.co.id/berita/qcidvs335/siswa-berkebutuhan-khususrentan-alami-degradasi-pendidikan

Hamidaturrohmah, H., \& Mulyani, T. (2020). STRATEGI PEMBELAJARAN JARAK JAUH SISWA BERKEBUTUHAN KHUSUS DI SD INKLUSI ERA PANDEMI COVID-19. ELEMENTARY: Islamic Teacher Journal, 8(2).

Amka, A. (2019). Pendidikan Inklusif Bagi Siswa Berkebutuhan Khusus di Kalimantan Selatan. Jurnal Pendidikan Dan Kebudayaan, 4(1), 86 - 101.

Tovstiga, N., \& Tovstiga, G. (2020). COVID-19: aknowledge and learning perspective. Knowledge Management Research and Practice, 00(00), 1-6. https://doi.org/10.1080/14778238.2020.1806749

Petcharat, M., \& Liehr, P. (2017). Mindfulness training for parents of children with special needs: Guidance for nurses in mental health practice. Journal of Child and Adolescent Psychiatric Nursing, 30(1), 35-46.

Ní Bhroin, Ó., \& King, F. (2020). Teacher education for inclusive education: a framework for developing collaboration for the inclusion of students with support plans. European Journal of Teacher Education, 43(1), 38-63.

Sandi, Elisabeth D. (2020, 5 November). 3 Strategi Atasi Tantangan PJJ Anak Berkebutuhan Khusus. Diakses pada 20 November 2020 dari 
https://edukasi.kompas.com/read/2020/11/05/111443271/3-strategi-atasitantangan-pjj-anak-berkebutuhan-khusus

Khoeriah, N. D. (2018). Individualized Educational Program dalam Implementasi Pendidikan Inklusif. INCLUSIVE: Journal of Special Education, 3(1).

Suherti, P. (2011). Penerapan Pembelajaran Kooperatif Tipe Student Teams Achievement Divisions (STAD) di Sekolah Inklusi (Studi Deskriptif tentang Inklusivitas Kelas dan Hasil Belajar Peserta Didik Slow Learner di Kelas V). JASSI ANAKKU, 10(1), 42-50.

Parmawati, S. B., Prasetyawati, W., \& Prianto, R. M. A. (2017). Efektivitas pendekatan modifikasi perilaku dengan teknik Fading dan token economy dalam meningkatkan kosakata siswa tuna rungu prelingual profound. Psibernetika, 8(1). 